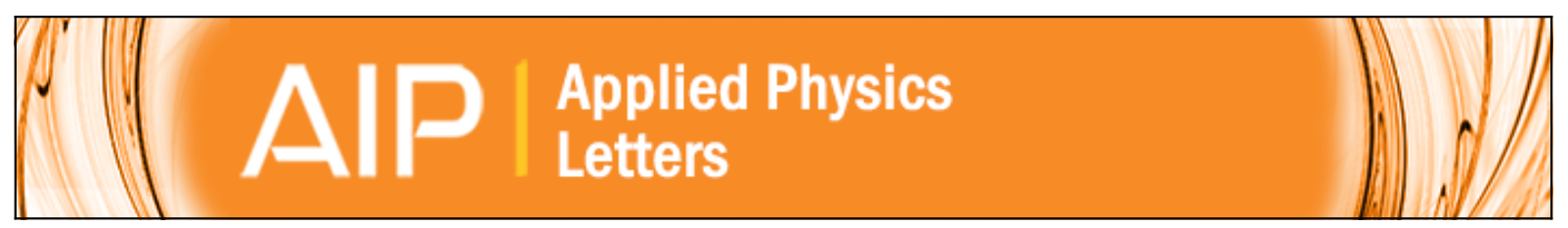

\title{
First-principles study on the effect of SiO2 layers during oxidation of $4 \mathrm{H}-\mathrm{SiC}$
}

Tomoya Ono and Shoichiro Saito

Citation: Applied Physics Letters 106, 081601 (2015); doi: 10.1063/1.4913598

View online: http://dx.doi.org/10.1063/1.4913598

View Table of Contents: http://scitation.aip.org/content/aip/journal/apl/106/8?ver=pdfcov

Published by the AIP Publishing

\section{Articles you may be interested in}

Deuterium absorption from the D2O exposure of oxidized $4 \mathrm{H}-\mathrm{SiC}(0001),\left(0001^{-}\right)$, and $\left(112^{-} 0\right)$ surfaces Appl. Phys. Lett. 106, 123502 (2015); 10.1063/1.4916266

Fabrication of $\mathrm{SiO} / 4 \mathrm{H}-\mathrm{SiC}$ (0001) interface with nearly ideal capacitance-voltage characteristics by thermal oxidation

Appl. Phys. Lett. 105, 032106 (2014); 10.1063/1.4891166

Diffusion of carbon oxides in $\mathrm{SiO} 2$ during $\mathrm{SiC}$ oxidation: A first-principles study

J. Appl. Phys. 113, 184312 (2013); 10.1063/1.4804665

Correlating macroscopic and nanoscale electrical modifications of $\mathrm{SiO} / 4 \mathrm{H}-\mathrm{SiC}$ interfaces upon post-oxidationannealing in $\mathrm{N} 2 \mathrm{O}$ and $\mathrm{POCl} 3$

Appl. Phys. Lett. 101, 193501 (2012); 10.1063/1.4766175

Characterization of thermally oxidized $\mathrm{Ti} / \mathrm{Si} \mathrm{O} 2$ gate dielectric stacks on $4 \mathrm{H}-\mathrm{SiC}$ substrate

Appl. Phys. Lett. 88, 072910 (2006); 10.1063/1.2173713

You don't

still use this

cell phone

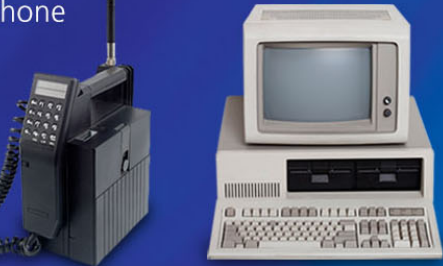

Why are you still using an AFM designed in the 80 's?
It is time to upgrade your AFM

Minimum $\$ 20,000$ trade-in discount for purchases before August 31st

Asylum Research is today's technology leader in AFM 


\title{
First-principles study on the effect of $\mathrm{SiO}_{2}$ layers during oxidation of $4 \mathrm{H}-\mathrm{SiC}$
}

\author{
Tomoya Ono ${ }^{1,2, a)}$ and Shoichiro Saito ${ }^{3}$ \\ ${ }^{1}$ Center for Computational Sciences, University of Tsukuba, Tsukuba, Ibaraki 305-8577, Japan \\ ${ }^{2}$ JST-PRESTO, Kawaguchi, Saitama 332-0012, Japan \\ ${ }^{3}$ Graduate School of Engineering, Osaka University, Suita, Osaka 565-0871, Japan
}

(Received 1 November 2014; accepted 15 February 2015; published online 23 February 2015)

\begin{abstract}
The effect of $\mathrm{SiO}_{2}$ layers during the thermal oxidation of a $4 \mathrm{H}-\mathrm{SiC}(0001)$ substrate is examined by performing the first-principles total-energy calculations. Although it is expected that a $\mathrm{CO}$ molecule is the most preferable product during the oxidation, $\mathrm{CO}_{2}$ molecules are mainly emitted from the $\mathrm{SiC}$ surface at the initial stage of the oxidation. As the oxidation proceeds, $\mathrm{CO}_{2}$ emission becomes less favorable and $\mathrm{CO}$ molecules are emitted from the interface. We conclude that the interface stress due to the lattice constant mismatch between $4 \mathrm{H}-\mathrm{SiC}(0001)$ and $\mathrm{SiO}_{2}$ is responsible for the removal of $\mathrm{C}$ during the oxidation, resulting in the characteristic electronic property of the interface fabricated by the thermal oxidation. (C) 2015 AIP Publishing LLC.

[http://dx.doi.org/10.1063/1.4913598]
\end{abstract}

Silicon carbide $(\mathrm{SiC})$ has attracted considerable attention owing to its excellent physical properties, such as its high thermal conductivity, high breakdown strength, and large band gap. It is also advantageous that the oxidation of $\mathrm{SiC}$ leads to $\mathrm{SiO}_{2}$, since it is well known that $\mathrm{SiO}_{2}$ exhibits good dielectric properties in Si device technology. Therefore, the application of $\mathrm{SiC}$ in metal-oxide-semiconductor field-effect transistors (MOSFETs) has been studied with the aim of realizing high-temperature, high-power, and high-frequency electronic devices. Among the numerous polytypes of $\mathrm{SiC}$, the $4 \mathrm{H}$ polytype has been recognized as the most promising material for applications because of its higher bulk mobility and larger band gap. However, unlike $\mathrm{Si}$ MOSFETs, SiC MOSFETs have unacceptably low carrier mobility. One of the origins of the low carrier mobility is the generation of a large number of interface defects at the $\mathrm{SiC} / \mathrm{SiO}_{2}$ interface during the thermal oxidation. Okamoto et al. ${ }^{1}$ reported that the carrier mobility increases when the interface defect density is reduced. To increase the carrier mobility of $\mathrm{SiC}$ MOSFETs, understanding and precise control of the electronic structure of the $\mathrm{SiC} / \mathrm{SiO}_{2}$ interface are indispensable.

Since $\mathrm{SiC}$ consists of the same number of $\mathrm{C}$ atoms and $\mathrm{Si}$ atoms, both $\mathrm{C}$ emission and $\mathrm{Si}$ emission ${ }^{2,3}$ during the oxidation process should be taken into account. The behavior of $\mathrm{C}$ atoms during oxidation is considered to play an important role, regardless of the interfacial atomic structure. The $\mathrm{C}$ emission process related to the $\mathrm{SiC} / \mathrm{SiO}_{2}$ interface has been studied by performing the first-principles calculations. Ventra and Pantelides ${ }^{4,5}$ studied the atomic-scale mechanism of the growth of the $\mathrm{SiO}_{2}$ region in cubic $\mathrm{SiC}$ bulk and concluded that a $\mathrm{SiO}_{2}$ molecule unit and a $\mathrm{CO}$ molecule are generated when three $\mathrm{O}$ atoms are inserted in the cubic $\mathrm{SiC}$ bulk. Knaup et al. ${ }^{6}$ and Deák et al. ${ }^{7}$ investigated the $\mathrm{CO}$ emission process by following the dry oxidation process of $\mathrm{SiC}$ using a $4 \mathrm{H}-\mathrm{SiC}(0001) / \mathrm{SiO}_{2}$ interface model. It is claimed that the reaction causing $\mathrm{CO}$ emission competes with that causing $\mathrm{C}$ cluster generation such as $\mathrm{C}$ or $\mathrm{C}_{2}$ interstitials. It is believed

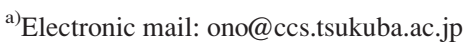

that $\mathrm{CO}$ molecules are dominantly emitted from the interface during the oxidation; although a $\mathrm{CO}_{2}$ molecule is the most stable product among the carbon oxides. However, there are no theoretical studies comparing the formation energies between the $\mathrm{CO}$ and $\mathrm{CO}_{2}$ emissions at an advancing $4 \mathrm{H}-\mathrm{SiC} /$ $\mathrm{SiO}_{2}$ interface because direct calculations of the atomic-scale processes that occur at the interface are computationally demanding. In particular, calculation of the formation energy of interface defects generated by oxidation requires a large supercell in the lateral direction.

In this study, first-principles calculations are carried out to examine the effect of $\mathrm{SiO}_{2}$ layers on the $\mathrm{C}$ removal process during the oxidation of a $4 \mathrm{H}-\mathrm{SiC}(0001)$ substrate. The most stable sites for each $\mathrm{O}$ atom inserted into a $\mathrm{Si}-\mathrm{C}$ bond are calculated by sequentially inserting $\mathrm{O}$ atoms between $\mathrm{Si}-$ $\mathrm{C}$ bonds to investigate the oxidation process of $\mathrm{SiC}$. It is found that the second $\mathrm{O}$ atoms enter the $\mathrm{Si}-\mathrm{C}$ bonds inside the substrate before the $\mathrm{Si}-\mathrm{C}$ bonds in the upper layer are oxidized so as to suppress the increase in the lattice constant mismatch between $4 \mathrm{H}-\mathrm{SiC}(0001)$ and $\mathrm{SiO}_{2}$. Then, the energy gains of $\mathrm{CO}$ and $\mathrm{CO}_{2}$ emissions are computed for each model by removing $\mathrm{C}$ and $\mathrm{O}$ atoms in the form of $\mathrm{CO}$ and $\mathrm{CO}_{2}$ molecules, respectively. Interestingly, $\mathrm{CO}_{2}$ emission preferentially occurs at the initial stage of the oxidation while $\mathrm{CO}$ emission becomes dominant as the oxidation proceeds. It is concluded that the interface stress due to the lattice constant mismatch plays an important role in the removal of $\mathrm{C}$. The $\mathrm{SiO}_{2}$ layers above the $\mathrm{SiC}$ substrate significantly affects the formation process of the interfaces during the thermal oxidation, which is relevant to the characteristic electronic property of the interface fabricated by the thermal oxidation. ${ }^{8}$

The first-principles calculations are performed within the framework of density functional theory ${ }^{9}$ using the realspace finite-difference approach, ${ }^{10-14}$ which provides us with the ground-state atomic and electronic structures using a time-saving double-grid technique. ${ }^{12-15}$ In addition, the realspace finite-difference method enables us to execute the large-scale calculation using massively parallel computers, 
thus this method is suitable for the total energy calculations including interface defects. The electron-ion interactions are treated using the projector augmented-wave method ${ }^{16}$ for the $\mathrm{C}, \mathrm{O}$, and $\mathrm{Si}$ atoms and using the norm-conserving pseudopotential ${ }^{17}$ of Troullier and Martins ${ }^{18,19}$ for $\mathrm{H}$ atoms. The exchange-correlation functional is approximated by the local density approximation. ${ }^{20}$ The coarse grid spacing of $0.16 \AA$ is used for all the calculations. Hereafter, the models for the initial and middle stages of the oxidation are referred to as the surface and interface models, respectively. For the calculation of the oxidation, the lateral size of the supercell is the $(6 \times 6 \sqrt{3}) 4 \mathrm{H}-\mathrm{SiC}(0001)$ surface, and the substrate contains five (four) $\mathrm{Si}-\mathrm{C}$ bilayers in the surface (interface) model. Dangling bonds at the bottommost $\mathrm{Si}-\mathrm{C}$ bilayer as well as those at the topmost layers of $\mathrm{SiO}_{2}$ are simply terminated by $\mathrm{H}$ atoms. The atomic structure of the initial surface for the thermal oxidation depends on the preparation of substrates. Since the studies exploring the epitaxial growth of a graphene on $\mathrm{SiC}$ surface report that bare $\mathrm{SiC}(0001)$ surfaces appear above $1000^{\circ} \mathrm{C}$ in vacuum, ${ }^{21}$ the bare surface is one of the realistic surface model. Thus, we chose the bare surface model for the initial oxidation. In the case of the interface model, although $\mathrm{SiO}_{2}$ forms an amorphous phase after the oxidation of $\mathrm{SiC}$, we assume that a crystalline structure remains locally near the $\mathrm{SiC} / \mathrm{SiO}_{2}$ interface, similarly to the $\mathrm{Si} / \mathrm{SiO}_{2}$ interface. ${ }^{22}$ Therefore, interfaces consisting of $\alpha$-quartz, $\alpha$-cristobalite, $\beta$-cristobalite, and $\beta$-tridymite $\mathrm{SiO}_{2}$ are considered. It is found that the $4 \mathrm{H}-\mathrm{SiC}(0001) / \beta$-tridymite $\mathrm{SiO}_{2}(001)$ interface has the smallest lattice constant mismatch among the interfaces. In addition, the ratio of the conduction band offset to valence band offset of the $4 \mathrm{H}-\mathrm{SiC} / \beta$ tridymite $\mathrm{SiO}_{2}$ interface is in good agreement with that obtained by X-ray photoelectron spectroscopy. The details of the determination of the interface atomic structures will be reported elsewhere. In the interface model, the oxide region contains $60 \mathrm{SiO}_{2}$ molecule units, i.e., the thickness of $\mathrm{SiO}_{2}$ is $\sim 15 \AA$. Thus, the computational model for the surface before the insertion of $\mathrm{O}$ atoms includes 264 atoms and that for the interface contains 400 atoms. The periodic boundary condition is applied in all directions and a sufficiently thick vacuum region of $\sim 14 \AA$ is inserted. Only the $\Gamma$ point is sampled in the Brillouin zone. We implement structural optimization until all the force components decrease to below $0.05 \mathrm{eV} / \mathrm{A}$. The atomic coordinates of the $\mathrm{Si}-\mathrm{C}$ bilayer in the bottommost layer and the $\mathrm{H}$ atoms terminating $\mathrm{C}$ dangling bonds are fixed during the structural optimization.
We first calculate the oxidation energies by sequentially inserting $\mathrm{O}$ atoms into $\mathrm{Si}-\mathrm{C}$ bonds around a particular $\mathrm{C}$ atom at the $4 \mathrm{H}-\mathrm{SiC}(0001)$ surface, assuming the initial stage of the oxidation. Figure 1 shows the computational model after the structural optimization. It has been theoretically proved that $\mathrm{O}_{2}$ molecules are the main species diffusing in the oxide during the oxidation. ${ }^{23}$ It has also been reported that an $\mathrm{O}_{2}$ molecule is not stable in $\mathrm{SiC}$ because of its relatively small interstitial volume and that it breaks into $\mathrm{Si}-\mathrm{C}$ bonds so as to form Si-O-C bonds. ${ }^{4}$ The oxidation energy for the insertion of an $\mathrm{O}$ atom into a $\mathrm{Si}-\mathrm{C}$ bond at the surface, $E_{n}^{\mathrm{ox}}$, is obtained from the expression

$$
E_{n}^{\mathrm{ox}}=E_{(n-1) \mathrm{O}}+\mu_{\mathrm{O}}-E_{n \mathrm{O}},
$$

where $n$ is the number of inserted $\mathrm{O}$ atoms, $E_{n \mathrm{O}}$ is the total energy of the system with $n \mathrm{O}$ atoms, and $\mu_{\mathrm{O}}$ is the chemical potential of an $\mathrm{O}$ atom calculated from the total energy of an $\mathrm{O}_{2}$ molecule. These values are determined by the density functional theory calculations at zero Kelvin.

Figure 2 shows the oxidation energy of the $\mathrm{SiC}$ surface for different values of $n$ (white bars). According to Eq. (1), the oxidation is preferable when the formation energy is positive. It is found that the oxidation energies of the SiC surface are smaller than those at the $\mathrm{Si}(001)$ surface $(3.0-5.0 \mathrm{eV}) .^{2}$ The first $\mathrm{O}$ atom prefers the site between the $\mathrm{Si}-\mathrm{C}$ bond in the first $\mathrm{Si}-\mathrm{C}$ bilayer. On the other hand, the most preferential site of the second $\mathrm{O}$ atom is the $\mathrm{Si}-\mathrm{C}$ bond between the first and second $\mathrm{Si}-\mathrm{C}$ bilayers so that the increase in the volume in the direction parallel to the surface is suppressed. In the case of $n=2$, the activation energy for the $\mathrm{O}_{2}$ molecule to the ground state configuration from the metastable configuration, where an $\mathrm{O}$ atom is in the $\mathrm{Si}-\mathrm{C}$ bond of the first bilayer and which is energetically high by $0.22 \mathrm{eV}$, is $\sim 1.5 \mathrm{eV}$. By considering an activation energy of about $1.2 \mathrm{eV}$ for the $\mathrm{O}_{2}$ molecule transport in silica measured by the thermal oxidation of $\mathrm{Si}$ substrates, ${ }^{24}$ some $\mathrm{O}$ atoms are stacked at the metastable configuration. The third $\mathrm{O}$ atom is preferentially inserted into the $\mathrm{Si}-\mathrm{C}$ bond in the first $\mathrm{Si}-\mathrm{C}$ bilayer again. We could not find the configuration in which three $\mathrm{O}$ atoms are inserted into the $\mathrm{Si}-\mathrm{C}$ bonds in the first $\mathrm{Si}$ C bilayer in the case of $n=3$.

To investigate the $\mathrm{C}$ removal process, we remove a $\mathrm{C}$ atom in the form of a $\mathrm{CO}$ or $\mathrm{CO}_{2}$ molecule from each model. Various possible sets of $\mathrm{C}$ and $\mathrm{O}$ atoms are removed from the oxidized surface and the most stable configuration is (a)

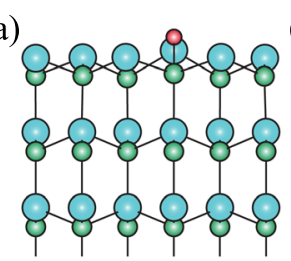

(e)

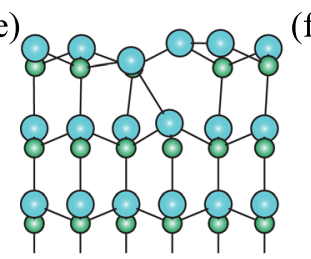

(b)

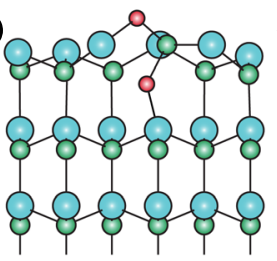

(f)

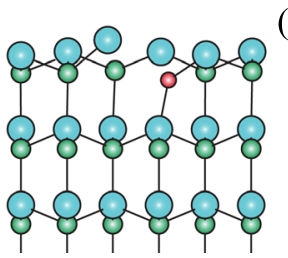

(c)

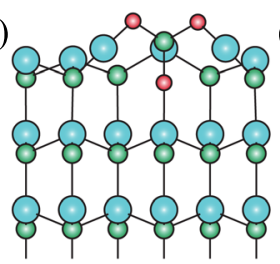

(g)

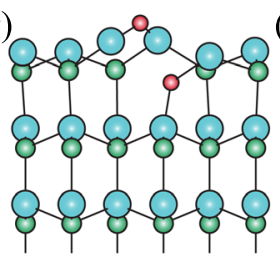

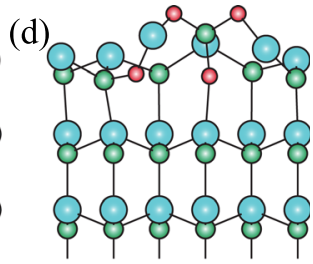

(h)

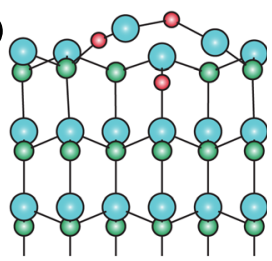

FIG. 1. 4H-SiC(0001) surface models with (a) $n=1$, (b) $n=2$, (c) $n=3$, and (d) $n=4$ before $\mathrm{C}$ removal. (e), (f), $(\mathrm{g})$, and $(\mathrm{h})$ Surface atomic structures after $\mathrm{CO}$ emission from (a), (b), (c), and (d), respectively. The models are the structures after the structural optimization. Green, red, and blue circles are $\mathrm{C}, \mathrm{O}$, and $\mathrm{Si}$ atoms, respectively. 


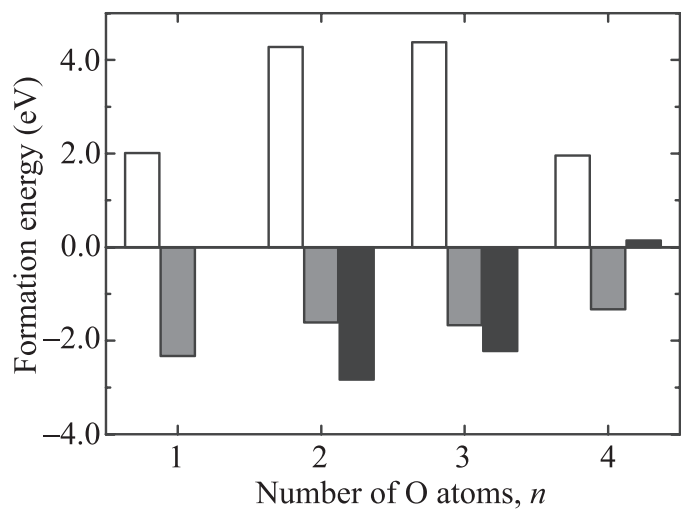

FIG. 2. Oxidation energies (white bars) and formation energies of $\mathrm{CO}$ emission (gray bars) and $\mathrm{CO}_{2}$ emission (black bars) at $\mathrm{SiC}$ surface for different numbers of inserted $\mathrm{O}$ atoms, $n$.

obtained. The energy gain of the emission from the system with $n \mathrm{O}$ atoms, $E_{n}^{\mathrm{CO}_{x}}$, is given by

$$
E_{n}^{\mathrm{CO}}=E_{n \mathrm{O}}^{\mathrm{w} / \mathrm{C}}-\left(E_{(n-x) \mathrm{O}}^{\mathrm{w} / \mathrm{oC}}+\mu_{\mathrm{CO}_{x}}\right)
$$

where $E_{n \mathrm{O}}^{\mathrm{w} / \mathrm{C}}, E_{(n-x) \mathrm{O}}^{\mathrm{w} / \mathrm{OC}}$, and $\mu_{\mathrm{CO}_{x}}$ are the total energy of the system with $n \mathrm{O}$ atoms, that with $(n-x) \mathrm{O}$ atoms with one $\mathrm{C}$ atom missing, and the total energy of a $\mathrm{CO}_{x}$ molecule, respectively. The calculated energies of the $\mathrm{CO}$ and $\mathrm{CO}_{2}$ emissions for different $n$ are shown in Fig. 2 by gray and black bars, respectively. Positive (negative) formation energy indicates that the $\mathrm{CO}_{x}$ emission is preferred (not preferred). Interestingly, a $\mathrm{CO}_{2}$ molecule is the most preferential species at the initial stage of oxidation contrary to the assumption employed in the experiments. ${ }^{25}$ It is also found that $\mathrm{CO}$ emission is not favorable, although a perfect $\mathrm{SiO}_{2}$ network is retained after $\mathrm{CO}$ emission in the case of $n=3$ (see Fig. 1(g)).

To further investigate the oxidation process of $\mathrm{SiC}$, we examine the emission of $\mathrm{C}$ from the $4 \mathrm{H}-\mathrm{SiC}(0001) / \mathrm{SiO}_{2}$ interface at the middle stage of the oxidation as shown in Fig. 3. Figures 3(b)-3(d) show the optimized atomic structures of the interface during the oxidation. The preferential sites for the inserted $\mathrm{O}$ atoms are the same to those of the

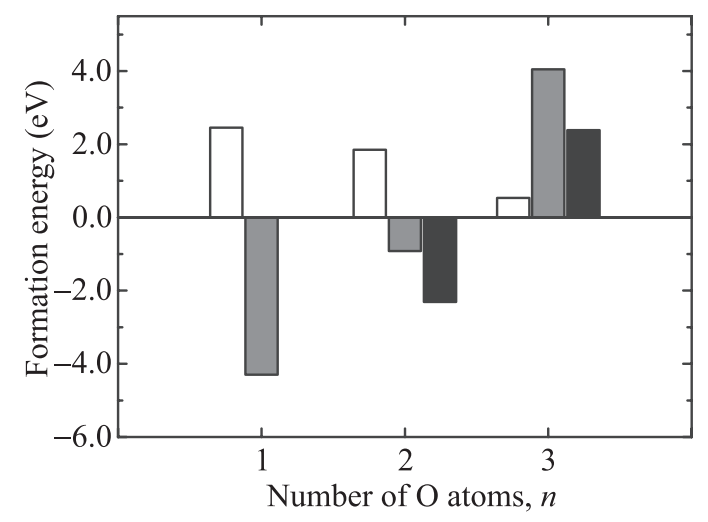

FIG. 4. Oxidation energies (white bars) and formation energies of $\mathrm{CO}$ emission (gray bars) and $\mathrm{CO}_{2}$ emission (black bars) at $\mathrm{SiC} / \mathrm{SiO}_{2}$ interface for different numbers of inserted $\mathrm{O}$ atoms, $n$.

surface oxidation: the second $\mathrm{O}$ atom is preferentially inserted at the site in the $\mathrm{Si}-\mathrm{C}$ bond connecting the first and second $\mathrm{Si}-\mathrm{C}$ bilayers, while the first and third $\mathrm{O}$ atoms prefer the site in the first bilayer. In addition, the situation concerning the energy difference between the configurations and activation energy is similar to that of the surface oxidation. The calculated oxidation energies of the $\mathrm{SiC} / \mathrm{SiO}_{2}$ interface defined by Eq. (1) are shown in Fig. 4. Since the oxidation energies at the interface are smaller than those at the surface, it is slightly more difficult for the oxidation to proceed at the interface. This is because the $\mathrm{SiO}_{2}$ on the $\mathrm{SiC}$ substrate prevents the interfacial atomic structure from relaxing.

Finally, we study the emission of $\mathrm{C}$ from the interface. The energy gains due to $\mathrm{CO}$ and $\mathrm{CO}_{2}$ emissions are shown in Fig. 4. CO emission preferentially occurs at $n=3$ because of the absence of Si dangling bonds and Si-O-C bonds after the emission (see Fig. 3(g)). On the other hand, $\mathrm{CO}_{2}$ is not the most preferential emission species because the oxidation energy of $\mathrm{Si}$ is much larger than that of $\mathrm{C}$; inserted $\mathrm{O}$ atoms are preferentially consumed to form $\mathrm{SiO}_{2}$ units.

The $\mathrm{CO}$ emission at $n=3$ and the $\mathrm{CO}_{2}$ emission at $n=4$ generate a perfect $\mathrm{SiO}_{2}$ network containing neither dangling bonds nor Si-O-C bonds. It is intuitive that the insertion of $\mathrm{O}$ atoms increases the volume, which causes the deformation

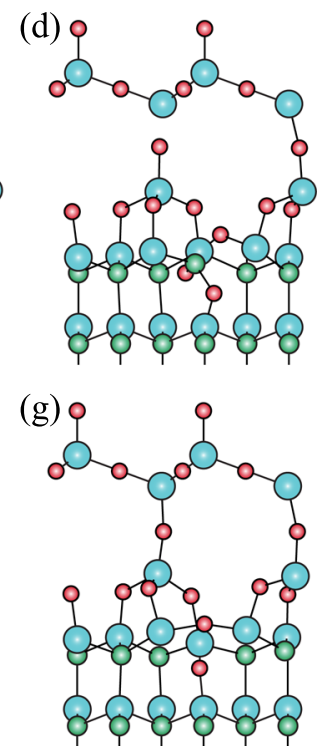

FIG. 3. $4 \mathrm{H}-\mathrm{SiC}(0001) / \beta$-tridymite $\mathrm{SiO}_{2}$ (010) interface model. (a) Before insertion of oxygen, (b) $n=1$, (c) $n=2$, and (d) $n=3$. (e), (f), and (g) Interface atomic structures after $\mathrm{CO}$ emission from (b), (c), and (d), respectively. The models are the structures after the structural optimization. The symbols have the same meaning as in Fig. 1. 
of the lattice. In the oxidation of the surface, the deformation of the lattice can be released owing to the absence of $\mathrm{SiO}_{2}$, resulting in the negative energy gain of $\mathrm{CO}$ emission. On the other hand, in the oxidation of the interface, the presence of $\mathrm{SiO}_{2}$ prevents the deformation of the lattice. Therefore, $\mathrm{CO}$ molecules are easily emitted from the interface so as to suppress the expansion of the $\mathrm{SiC}$ substrate when three $\mathrm{O}$ atoms are inserted.

Our results indicate that the formation of the interfaces is affected by the interface stress due to the lattice constant mismatch between $4 \mathrm{H}-\mathrm{SiC}(0001)$ and $\mathrm{SiO}_{2}$. It is known that the electronic structure of the interface fabricated by the thermal oxidation shows different characteristics from that formed by the oxide deposition. ${ }^{8}$ The interface stress causes this difference in the electronic structure during the thermal oxidation.

In summary, we have conducted a systematic study of the $\mathrm{C}$ removal process during the oxidation of a $4 \mathrm{H}$ $\mathrm{SiC}(0001)$ substrate by first-principles calculations. It is revealed that the oxidation energy of $\mathrm{SiC}(0001)$ is smaller than that of $\mathrm{Si}(001)$. The most stable site for the second inserted $\mathrm{O}$ atom is at the middle of the $\mathrm{Si}-\mathrm{C}$ bond connecting the first and second $\mathrm{Si}-\mathrm{C}$ bilayers for both the $\mathrm{SiC}(0001)$ surface and the $\mathrm{SiC}(0001) / \mathrm{SiO}_{2}$ interface. More interestingly, by calculating the total energy of an advancing $4 \mathrm{H}-\mathrm{SiC} / \mathrm{SiO}_{2}$ interface, we found that $\mathrm{CO}_{2}$ molecules are the most preferential species at the initial stage of oxidation, which is different from the conventional expectation. As the $\mathrm{SiO}_{2}$ layer grows, $\mathrm{CO}$ emission becomes favorable. By examining the atomic structures before and after the emissions, we conclude that the presence of $\mathrm{SiO}_{2}$ above the $\mathrm{SiC}$ substrate plays an important role in determining the emission species as well as in relaxing the bonding networks at the oxidation front, which gives rise to the difference in the electronic structures between the interfaces fabricated by the thermal oxidation and oxide deposition.

The authors would like to thank Professor Heiji Watanabe and Professor Takuji Hosoi of Osaka University, Japan for contributing to our fruitful discussions. This research was partially supported by the Computational
Materials Science Initiative (CMSI) and a Grantin-Aid for Scientific Research on Innovative Areas (Grant No. 22104007) from the Ministry of Education, Culture, Sports, Science and Technology, Japan. The numerical calculations were carried out using the computer facilities of the Institute for Solid State Physics at the University of Tokyo, the Center for Computational Sciences at University of Tsukuba, and $\mathrm{K}$ computer under a trial use at Advanced Institute for Computational Science at RIKEN.

${ }^{1}$ D. Okamoto, H. Yano, K. Hirata, T. Hatayama, and T. Fuyuki, IEEE Electron Device Lett. 31, 710 (2010).

${ }^{2}$ H. Kageshima and K. Shiraishi, Phys. Rev. Lett. 81, 5936 (1998).

${ }^{3}$ Z. Ming, K. Nakajima, M. Suzuki, K. Kimura, M. Uematsu, K. Torii, S. Kamiyama, Y. Nara, and K. Yamada, Appl. Phys. Lett. 88, 153516 (2006).

${ }^{4}$ M. Di Ventra and S. T. Pantelides, Phys. Rev. Lett. 83, 1624 (1999).

${ }^{5}$ M. Ventra and S. Pantelides, J. Electron. Mater. 29, 353 (2000).

${ }^{6}$ J. M. Knaup, P. Deák, T. Frauenheim, A. Gali, Z. Hajnal, and W. J. Choyke, Phys. Rev. B 71, 235321 (2005).

${ }^{7}$ P. Deák, A. Gali, J. Knaup, Z. Hajnal, T. Frauenheim, P. Ordejón, and J. Choyke, Physica B 340-342, 1069 (2003).

${ }^{8}$ C. Kim, J. H. Moon, J. H. Yim, D. H. Lee, J. H. Lee, H. H. Lee, and H. J. Kim, Appl. Phys. Lett. 100, 082112 (2012).

${ }^{9}$ P. Hohenberg and W. Kohn, Phys. Rev. 136, B864 (1964).

${ }^{10}$ J. R. Chelikowsky, N. Troullier, and Y. Saad, Phys. Rev. Lett. 72, 1240 (1994).

${ }^{11}$ J. R. Chelikowsky, N. Troullier, K. Wu, and Y. Saad, Phys. Rev. B 50, 11355 (1994)

${ }^{12}$ T. Ono and K. Hirose, Phys. Rev. Lett. 82, 5016 (1999).

${ }^{13}$ T. Ono and K. Hirose, Phys. Rev. B 72, 085115 (2005).

${ }^{14}$ T. Ono, M. Heide, N. Atodiresei, P. Baumeister, S. Tsukamoto, and S. Blügel, Phys. Rev. B 82, 205115 (2010).

${ }^{15}$ K. Hirose, T. Ono, Y. Fujimoto, and S. Tsukamoto, First Principles Calculations in Real-Space Formalism, Electronic Configurations and Transport Properties of Nanostructures (Imperial College, London, 2005). ${ }^{16}$ P. E. Blöchl, Phys. Rev. B 50, 17953 (1994).

${ }^{17}$ We used the norm-conserving pseudopotentials NCPS97 constructed by K. Kobayashi; see K. Kobayashi, Comput. Mater. Sci. 14, 72 (1999).

${ }^{18}$ N. Troullier and J. L. Martins, Phys. Rev. B 43, 1993 (1991).

${ }^{19}$ L. Kleinman and D. M. Bylander, Phys. Rev. Lett. 48, 1425 (1982).

${ }^{20}$ S. H. Vosko, L. Wilk, and M. Nusair, Can. J. Phys. 58, 1200 (1980).

${ }^{21}$ C. Berger, Z. Song, T. Li, X. Li, A. Y. Ogbazghi, R. Feng, Z. Dai, A. N. Marchenkov, E. H. Conrad, P. N. First, and W. A. de Heer, J. Phys. Chem. B 108, 19912 (2004).

${ }^{22}$ K. Tatsumura, T. Watanabe, D. Yamasaki, T. Shimura, M. Umeno, and I. Ohdomari, Phys. Rev. B 69, 085212 (2004).

${ }^{23}$ A. Bongiorno and A. Pasquarello, Phys. Rev. B 70, 195312 (2004).

${ }^{24}$ B. E. Deal and A. S. Grove, J. Appl. Phys. 36, 3770 (1965).

${ }^{25}$ R. H. Kikuchi and K. Kita, Appl. Phys. Lett. 105, 032106 (2014). 